UDC 517.9

DOI: $10.32626 / 2308-5916.2018-18.5-17$

A. Bomba, Doctor of Engineering, Professor, K. Malash, Ph. D. Student

Rivne State Humanitarian University, Rivne

\title{
MODELING OF EXPLOSIVE PROCESSES IN ANISOTROPIC MEDIA WHERE BOUNDARY OF THE INFLUENCE REGION IS IDENTIFIED
}

Nowadays, explosive processes are widely used for the optimization of extraction minerals processes, in the buildings construction and industry. This practice allows to significantly increase the speed of the work and, at the same time, reduce it cost. However, side effects of the explosion usage can be catastrophic, since its destructive power is capable of completely demolishing even fairly stable buildings and causing irreparable damage to the environment, therefore there is a need for a precise mathematical modeling of the explosive process with a detailed calculation of all its consequences.

One of the models used to investigate the explosion process is a fluid based on the simulation of an environment in which an explosion occurs as a filtration fluid. In this case, the velocity field generated by the explosion is usually considered to be potential.

This article deals with a mathematical model of the explosion process based on a liquid model. It takes into account the mutual influence of the deformable anisotropic porous medium parameters and the explosive process characteristics. The corresponding boundary value problem is solved using the numerical quasiconformal mappings method which ensures the possibility of its solution taking into account the presence of the reverse effect, the existence of which essentially complicates the process of solving the problem by other, less «dynamical» methods. Algorithm used in the modelling of similar processes in hydrodynamics and electrodynamics, in particular for the study of filtration processes and electromotography is adapted for solving appropriate boundary value problems. The method of identifying the external boundary of the domain of the explosive process influence is developed by introducing certain changes to the «classical» algorithm for solving such a type of boundary problems for the twice-bounded domain since the last one requires a priori assignment of the inner and outer domain contours.

Key words: anisotropic medium, complex analysis, explosion processes, hydrodynamic mesh, identification, mathematical modelling, numerical methods, quasiconformal mapping.

Introduction. Explosive processes are often used in mining, particularly, for grinding the hard rock preventing easily access to the minerals at the present stage of development of production. Also, explosions are often 
used in buildings construction, for example, to clear the territory or create large depths. It is extremely important to determine the correct technological parameters of the explosion process, since the inaccuracies made may couth to catastrophic consequences, particularly, the destruction of nearby buildings, or the other significant damage, the elimination of which requires enormous costs or is impossible. For this purpose, mathematical modeling of the process is carried out.

Nowadays there are several models of explosion processes, each of which is used by various researchers. Particularly, V. Kravets, V. Korobichychuk, V. Boyko use linear-elastic, elastic-plastic and visco-elastic ones [1]. V. Bulavatskii, V. Skopetskii, and I. Luchko consider the liquid model based on the representation of the medium in which the explosion occurs as an ideal liquid, and the field formed by the explosion is considered to be a potential. In this case the process modelling is based on the solution of the corresponding boundary value problem using conformal mappings. However, their functional does not provide sufficient accuracy of the solution, since the field formed as a result of the explosion is not ideal (this is due to the presence of squeezed parts of the soil, as well as areas close to the cavities); in addition, there is a need to take into account the reciprocal influence of process characteristics and the medium characteristics. The liquid model of explosive processes was improved by A. Bomba and his scientific school [4-5]. Quasiconformal mappings methods are used for solving the corresponding boundary value problem [6-10]. The impact of the explosive process on an isotropic medium is investigated in [4], the impact on anisotropic one is described in [5] (the boundaries of crater, pressed and undisturbed sections of the medium are determined, and, also, the hydrodynamic grid of the formed field is constructed). The area of an explosion influence is considered to be given a priori in these works (the corresponding mathematical domain is modeled as a twice-bounded domain).

In this article we propose a solution to the problem of determining the boundaries of the crater, pressed and undisturbed domains of the medium with the simultaneous identification of the area boundary of the explosion impact on the investigated environment, taking into account the interaction of the characteristics of the environment and the process with the automatic construction of the hydrodynamic grid.

Presenting main material. We consider a certain domain $G_{z}$ $(z=x+i y)$, where the charge of a given form with a constant quasipotential on it is placed, in a medium where an explosion was occurred (Fig. 1). 


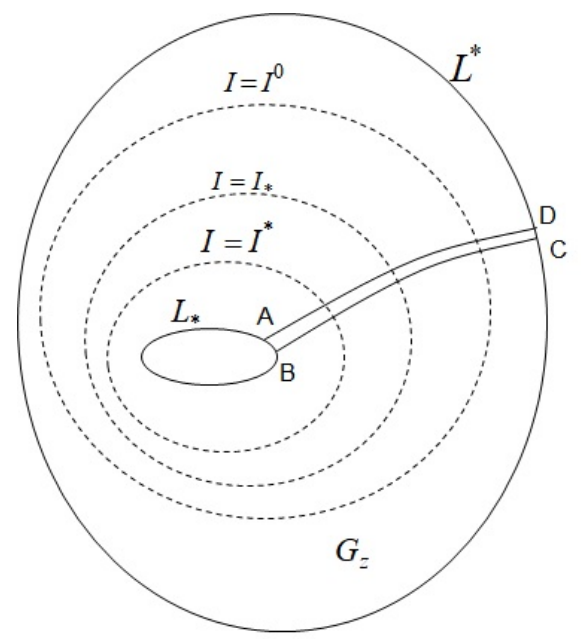

Fig. 1. Physical domain of the medium

The particles motion process is described (analogously to [5]) by the motion equation $\vec{v}=k \operatorname{grad} \varphi$ and the continuity equation $\operatorname{div} \vec{v}=0$, where $\vec{v}=\left(v_{x}(x, y), v_{y}(x, y)\right)$ is the particle velocity, and $\varphi=\varphi(x, y)$ is the quasi-potential of the corresponding field,

$$
k=\left(\begin{array}{ll}
k_{11}\left(x, y, \varphi_{x}, \varphi_{y}\right) & k_{12}\left(x, y, \varphi_{x}, \varphi_{y}\right) \\
k_{21}\left(x, y, \varphi_{x}, \varphi_{y}\right) & k_{22}\left(x, y, \varphi_{x}, \varphi_{y}\right)
\end{array}\right)
$$

is the conductivity coefficient of the medium (which characterizes the ability of particles to rise). We consider that the explosion influence area is bounded by two contours - external and internal ones. The inner contour is the charge boundary. It is known a priori:

$$
L_{*}=\left\{z: f_{*}(x, y)=0\right\}=\left\{x+i y: x=x_{*}(t), y=y_{*}(t), \alpha_{*}<t<\beta_{*}\right\} .
$$

The outer contour of the domain separates the studied area from the general one, and we can't set it a priori. Physically, it delimits the soil areas with the same characteristics, because the undisturbed zone of soil from the studied domain has the same characteristics as the outside one, so the external contour, which is established solely for the purpose of correct calculation, should be chosen so that it is situated in the undisturbed zone (emphasize that the contour that separates the pressed and the undisturbed soil zone is important to know from a practical point of view). It is inappropriate to choose the outer contour so that the undisturbed area within the studied area is too large, since an increase in the size of the studied area requires an increase in the number of the partition nodes, which leads 
to higher costs of machine time or to the loss of accuracy; on the other hand, the choice of the external contour so that it would be outside the unbroken area will result in distortion of the results. We propose to identify the outer contour of the investigated area by solving a sequence of similar tasks, each of which differs from the previous one by outer contour. After solving each of the following tasks (starting with the second one), we compare the obtained boundaries of the crater, the pressed and undisturbed domains of the soil with those obtained for the previous. If they coincide with sufficient accuracy, then the contour that we found in the first of the comparable tasks is the wanted one; otherwise, we go to solving the next problem, in which we consider a little bit "larger" area. the process should be repeated until the desired boundaries of the crater, pressed and undisturbed domains of soil in the two adjacent tasks do not coincide. So, in each of the subtasks the outer contour is set in such way:

$$
L_{s}^{*}=\left\{z: f^{*}(x, y)=0\right\}==\left\{x+i y: x=x_{s}^{*}(t), y=y_{s}^{*}(t), \alpha^{*}<t<\beta^{*}\right\},
$$

where $\left.\varphi\right|_{L_{*}}=\varphi_{*},\left.\varphi\right|_{L_{s}^{*}}=\varphi^{*},-\infty<\varphi_{*}<\varphi^{*}<+\infty$. In each task from the considered sequence, the functions $x_{s}^{*}(t), y_{s}^{*}(t)$ have the same structure and differ only in parameters in such a way that they form a sequence of so-called «concentric» contours.

As a result of the problem solution it is necessary to construct a hydrodynamic grid, to determine the boundaries of the crater, the pressed and undisturbed sections of the soil (in Fig. 1, these borders are marked by dashed lines $I=I^{*}, I=I^{0}$ ).

We model the explosion process in the same way as [5] - taking into account the interaction of the quasipotential $\varphi=\varphi(x, y)$ gradient $I=\sqrt{\varphi_{x}^{2}+\varphi_{y}^{2}}$ and the conductivity tensor $k=\left(\begin{array}{ll}k_{11} & k_{12} \\ k_{21} & k_{22}\end{array}\right)$ and the formation of the sections (Fig. 1), in which the correction of the latter is made, depending on the values $I$ according to the following formula:

$$
k_{r s}=k_{0 r s}+\frac{1}{2} \beta_{r s}\left(I-I^{*}\right)\left(\left(I-I^{0}\right)+\left|I-I^{0}\right|\right),(r, s=1,2),
$$

where $I^{0}, I^{*}$ are the critical gradient values, which characterize the delay and separation of particles (the position of the line of the section), the parameter tensor $\beta=\left(\begin{array}{ll}\beta_{11} & \beta_{12} \\ \beta_{21} & \beta_{22}\end{array}\right)$, which characterizes the medium anisotropy change, is selected based on the physical experiment [3]. 
We introduce a flow function $\psi=\psi(x, y)$, that is complex conjugate to $\varphi=\varphi(x, y)$ (as described in [7]), fix a certain point $A=B \in L_{*}$ on the inner contour of the domain and make a conditional incision of the investigated domain along one of the flow lines (unknown yet, it will be refined in the process of problem solving). The top and bottom of the section are marked via AA and BB on Fig. 1. We obtain (in the case of a fixed $k$ ) the problem on a quasiconformal mapping $\omega=\omega(z)=\varphi(x, y)+\mathrm{i} \psi(x, y)$ [6] formed by a single-bounded domain $G_{z}^{0}=G_{z} / A \underline{A}$ on the corresponding rectangular domain of a complex quasipotential $G_{\omega}=\left\{\omega=\varphi+i \psi: \varphi_{*}<\varphi<\varphi^{*}, 0<\psi<Q\right\}$ with an unknown parameter $Q$ :

$$
\begin{aligned}
& \kappa_{11}\left(x, y, \varphi_{x}, \varphi_{y}\right) \frac{\partial \varphi}{\partial x}+\kappa_{12}\left(x, y, \varphi_{x}, \varphi_{y}\right) \frac{\partial \varphi}{\partial y}=\frac{\partial \psi}{\partial y}, \\
& \kappa_{21}\left(x, y, \varphi_{x}, \varphi_{y}\right) \frac{\partial \varphi}{\partial x}+\kappa_{22}\left(x, y, \varphi_{x}, \varphi_{y}\right) \frac{\partial \varphi}{\partial y}=-\frac{\partial \psi}{\partial x},(x, y) \in G_{z}^{0} . \\
& \varphi_{L_{*}}=\varphi_{*}, \quad \varphi_{L_{s}^{*}}=\varphi^{*},\left.\quad \psi\right|_{A \underline{A}}=0,\left.\psi\right|_{B \underline{B}}=Q=\oint_{L_{*}}-v_{y} d x+v_{x} d y .
\end{aligned}
$$

The corresponding inverse boundary value problem on the quasiconformal mapping $z=z(\omega)=x(\varphi, \psi)+i y(\varphi, \psi)$ of the domain $G_{\omega}$ on $G_{z}^{0}$ and the real $x=x(\varphi, \psi)$ and imaginary $y=y(\varphi, \psi)$ parts equation (we also require it's execution in the section to account for their «split» in the transition from the domain $G_{z}$ to $G_{\omega}$ ) of the characteristic flow function with the unknown position of the section and the value $Q$ is obsessed as:

$$
\begin{gathered}
\kappa_{11}\left(x, y, \frac{y_{\psi}}{J},-\frac{x_{\psi}}{J}\right) \frac{\partial y}{\partial \psi}-\kappa_{12}\left(x, y, \frac{y_{\psi}}{J},-\frac{x_{\psi}}{J}\right) \frac{\partial x}{\partial \psi}=\frac{\partial x}{\partial \varphi} \\
\kappa_{21}\left(x, y, \frac{y_{\psi}}{J},-\frac{x_{\psi}}{J}\right) \frac{\partial y}{\partial \psi}-\kappa_{22}\left(x, y, \frac{y_{\psi}}{J},-\frac{x_{\psi}}{J}\right) \frac{\partial x}{\partial \psi}=\frac{\partial y}{\partial \varphi} \\
(\varphi, \psi) \in G, \quad J=x_{\varphi} y_{\psi}-x_{\psi} y_{\varphi}, \\
f_{*}\left(x\left(\varphi_{*}, \psi\right), y\left(\varphi_{*}, \psi\right)\right)=0, \quad \varphi_{*} \leq \varphi \leq \varphi^{*} \\
f_{s}^{*}\left(x\left(\varphi^{*}, \psi\right), y\left(\varphi^{*}, \psi\right)\right)=0, \quad 0 \leq \psi \leq Q \\
x(\varphi, 0)=x(\varphi, Q), \quad y(\varphi, 0)=y(\varphi, Q), \quad \varphi_{*}<\varphi<\varphi^{*},
\end{gathered}
$$




$$
\begin{gathered}
\frac{\partial}{\partial \varphi}\left(\frac{1}{\kappa_{11}} \frac{\partial x}{\partial \varphi}\right)+\frac{\partial}{\partial \psi}\left(\frac{\kappa_{11} \kappa_{22}-\kappa_{21} \kappa_{12}}{\kappa_{11}} \frac{\partial x}{\partial \psi}\right)+\frac{\partial}{\partial \varphi}\left(\frac{\kappa_{12}}{\kappa_{11}} \frac{\partial x}{\partial \psi}\right)- \\
-\frac{\partial}{\partial \psi}\left(\frac{\kappa_{21}}{\kappa_{11}} \frac{\partial x}{\partial \varphi}\right)=0, \frac{\partial}{\partial \varphi}\left(\frac{1}{\kappa_{22}} \frac{\partial y}{\partial \varphi}\right)+ \\
+\frac{\partial}{\partial \psi}\left(\frac{\kappa_{11} \kappa_{22}-\kappa_{21} \kappa_{12}}{\kappa_{22}} \frac{\partial y}{\partial \psi}\right)-\frac{\partial}{\partial \varphi}\left(\frac{\kappa_{21}}{\kappa_{22}} \frac{\partial y}{\partial \psi}\right)+\frac{\partial}{\partial \psi}\left(\frac{\kappa_{12}}{\kappa_{22}} \frac{\partial y}{\partial \varphi}\right)=0 .
\end{gathered}
$$

We construct the algorithm for numerical solution of the problem analogously to [5]. The difference analogs of equations (6), boundary conditions (4), as well as additional conditions for boundary and nearboundary nodes in the corresponding uniform grid domain

$$
\begin{gathered}
G_{\omega}^{\gamma}=\left\{\left(\varphi_{i}, \psi_{j}\right): \varphi_{i}=\varphi_{*}+i \cdot \Delta \varphi, i=\overline{0, n} ; \psi_{j}=j \cdot \Delta \psi, j=\overline{0, m} ;\right. \\
\left.\Delta \varphi=\frac{\varphi^{*}-\varphi_{*}}{n}, \Delta \psi=\frac{Q}{m}, \gamma=\frac{\Delta \psi}{\Delta \varphi}\right\}
\end{gathered}
$$

is written, respectively, in the form:

$$
\begin{gathered}
\sigma\left(\widehat{a}_{i+1, j+1} x_{i+1, j+1}-\left(\widehat{a}_{i+1, j+1}+\widehat{a}_{i, j+1}\right) x_{i, j+1}+\widehat{a}_{i, j+1} x_{i-1, j+1}\right)+ \\
(1-2 \sigma)\left(\widehat{a}_{i+1, j} x_{i+1, j}-\left(\widehat{a}_{i+1, j}+\widehat{a}_{i, j}\right) x_{i, j}+\widehat{a}_{i, j} x_{i-1, j}\right)+ \\
+\sigma\left(\widehat{a}_{i+1, j-1} x_{i+1, j-1}-\left(\widehat{a}_{i+1, j-1}+\widehat{a}_{i, j-1}\right) x_{i, j-1}+\widehat{a}_{i, j-1} x_{i-1, j-1}\right)+ \\
+\gamma^{2}\left(\sigma\left(\widehat{b}_{i+1, j+1} x_{i+1, j+1}-\left(\widehat{b}_{i+1, j+1}+\widehat{b}_{i+1, j}\right) x_{i+1, j}+\widehat{b}_{i+1, j} x_{i+1, j-1}\right)+\right. \\
+(1-2 \sigma)\left(\widehat{b}_{i, j+1} x_{i, j+1}-\left(\widehat{b}_{i, j+1}+\widehat{b}_{i, j}\right) x_{i, j}+\widehat{b}_{i, j} x_{i, j-1}\right)+ \\
\left.+\sigma\left(\widehat{b}_{i-1, j+1} x_{i-1, j+1}-\left(\widehat{b}_{i-1, j+1}+\widehat{b}_{i-1, j}\right) x_{i-1, j}+\widehat{b}_{i-1, j} x_{i-1, j-1}\right)\right)+ \\
+\gamma\left(\widehat{c}_{i+1, j}\left(x_{i+1, j+1}-x_{i+1, j-1}\right)-\widehat{c}_{i-1, j}\left(x_{i-1, j+1}-x_{i-1, j-1}\right)-\right. \\
-\widehat{d}_{i, j+1}\left(x_{i+1, j+1}-x_{i-1, j+1}\right)+\widehat{d}_{i, j-1}\left(x_{i+1, j-1}-x_{i-1, j-1}\right) / 4=0 \\
\sigma\left(\breve{a}_{i+1, j+1} y_{i+1, j+1}-\left(\breve{a}_{i+1, j+1}+\breve{a}_{i, j+1}\right) y_{i, j+1}+\breve{a}_{i, j+1} y_{i-1, j+1}\right)+ \\
+(1-2 \sigma)\left(\breve{a}_{i+1, j} y_{i+1, j}-\left(\breve{a}_{i+1, j}+\breve{a}_{i, j}\right) y_{i, j}+\breve{a}_{i, j} y_{i-1, j}\right)+ \\
+\sigma\left(\breve{a}_{i+1, j-1} y_{i+1, j-1}-\left(\breve{a}_{i+1, j-1}+\breve{a}_{i, j-1}\right) y_{i, j-1}+\breve{a}_{i, j-1} y_{i-1, j-1}\right)+ \\
+\gamma^{2}\left(\sigma\left(\breve{b}_{i+1, j+1} y_{i+1, j+1}-\left(\breve{b}_{i+1, j+1}+\breve{b}_{i+1, j}\right) y_{i+1, j}+\breve{b}_{i+1, j} y_{i+1, j-1}\right)+\right.
\end{gathered}
$$




$$
\begin{gathered}
+(1-2 \sigma)\left(\breve{b}_{i, j+1} y_{i, j+1}-\left(\breve{b}_{i, j+1}+\breve{b}_{i, j}\right) y_{i, j}+\breve{b}_{i, j} y_{i, j-1}\right)+ \\
\left.+\sigma\left(\breve{b}_{i-1, j+1} y_{i-1, j+1}-\left(\breve{b}_{i-1, j+1}+\breve{b}_{i-1, j}\right) y_{i-1, j}+\breve{b}_{i-1, j} y_{i-1, j-1}\right)\right)+ \\
+\gamma\left(-\breve{c}_{i+1, j}\left(y_{i+1, j+1}-y_{i+1, j-1}\right)+\breve{c}_{i-1, j}\left(y_{i-1, j+1}-y_{i-1, j-1}\right)+\right. \\
\left.+\breve{d}_{i, j+1}\left(y_{i+1, j+1}-y_{i-1, j+1}\right)-\breve{d}_{i, j-1}\left(y_{i+1, j-1}-y_{i-1, j-1}\right)\right) / 4=0, \\
i=\overline{1, m}, \quad j=\overline{1, n} .
\end{gathered}
$$

Where

$$
\begin{aligned}
& \widehat{a}_{i, j}=a c\left(\frac{1}{\kappa_{i, j}^{11}}\right), \widehat{b}_{i, j}=b d\left(\frac{\kappa_{i, j}^{11} \kappa_{i, j}^{22}-\kappa_{i, j}^{21} \kappa_{i, j}^{12}}{\kappa_{i, j}^{11}}\right), \widehat{c}_{i, j}=a c\left(\frac{\kappa_{i, j}^{12}}{\kappa_{i, j}^{11}}\right), \\
& \widehat{d}_{i, j}=b d\left(\frac{\kappa_{i, j}^{21}}{\kappa_{i, j}^{11}}\right), \breve{a}_{i, j}=a c\left(\frac{1}{\kappa_{i, j}^{22}}\right), \breve{b}_{i, j}=b d\left(\frac{\kappa_{i, j}^{11} \kappa_{i, j}^{22}-\kappa_{i, j}^{21} \kappa_{i, j}^{12}}{\kappa_{i, j}^{22}}\right) \text {, } \\
& \breve{c}_{i, j}=a c\left(\frac{\kappa_{i, j}^{21}}{\kappa_{i, j}^{22}}\right), \breve{d}_{i, j}=b d\left(\frac{\kappa_{i, j}^{12}}{\kappa_{i, j}^{22}}\right) \text {; } \\
& a c\left(k_{i, j}\right)=\frac{k_{i, j}+k_{i-1, j}}{2}, b d\left(k_{i, j}\right)=\frac{k_{i, j}+k_{i, j-1}}{2} \text {. } \\
& \kappa_{i, j}^{r s}=\kappa_{r s}\left(\frac{2 \Delta \varphi\left(y_{i, j+1}-y_{i, j-1}\right)}{J_{i, j}}, \frac{2 \Delta \varphi\left(x_{i, j-1}-x_{i, j+1}\right)}{J_{i, j}}\right) . \\
& J_{i, j}=\left(x_{i+1, j}-x_{i-1, j}\right)\left(y_{i, j+1}-y_{i, j-1}\right)-\left(x_{i, j+1}-x_{i, j-1}\right)\left(y_{i+1, j}-y_{i-1, j}\right) \text {, } \\
& i=\overline{1, m}, j=\overline{1, n} \text {. } \\
& \left(-f_{*_{x}}^{\prime}\left(x_{0, j}, y_{0, j}\right)\left(y_{1, j}-y_{0, j}\right)+f_{*_{y}}^{\prime}\left(x_{0, j}, y_{0, j}\right)\left(x_{1, j}-x_{0, j}\right)=\right. \\
& =\sqrt{f_{*_{x}}^{\prime 2}\left(x_{0, j}, y_{0, j}\right)+f_{* y}^{\prime 2}\left(x_{0, j}, y_{0, j}\right)} \times \\
& \times \sqrt{\left(x_{1, j}-x_{0, j}\right)^{2}+\left(y_{1, j}-y_{0, j}\right)^{2}} \sqrt{1-\cos ^{2} \Theta_{* 0, j}}, \\
& f_{s}^{* \prime}\left(x_{i, n+1}, y_{i, n+1}\right)\left(y_{i, n}-y_{i, n+1}\right)-f_{s}^{* \prime}\left(x_{i, n+1}, y_{i, n+1}\right)\left(x_{i, n}-x_{i, n+1}\right)= \\
& =\sqrt{f_{s}^{* \prime} x^{2}\left(x_{i, n+1}, y_{i, n+1}\right)+f_{s}^{* \prime} y^{2}\left(x_{i, n+1}, y_{i, n+1}\right)} \times \\
& \times \sqrt{\left(x_{i, n}-x_{i, n+1}\right)^{2}+\left(y_{i, n}-y_{i, n+1}\right)^{2}} \sqrt{1-\cos ^{2} \Theta_{i, n+1}^{*}} \text {, }
\end{aligned}
$$


where

$$
\begin{aligned}
& \cos \Theta=\left(\kappa_{11} f_{x}^{\prime 2}+\left(\kappa_{12}+\kappa_{21}\right) f_{x}^{\prime} f_{l y}^{\prime}+\kappa_{22} f_{y}^{\prime 2}\right) /\left(f_{x}^{\prime 2}+\right. \\
& \left.\left.+f_{y}^{\prime} 2\right)^{\frac{1}{2}}\left(\left(\kappa_{11} f_{x}^{\prime}+\kappa_{12} f_{y}^{\prime}\right)^{2}+\left(\kappa_{21} f_{x}^{\prime}+\kappa_{22} f_{y}^{\prime}\right)^{2}\right)^{\frac{1}{2}}\right) .
\end{aligned}
$$

The approximation magnitude $\gamma$ formula is obtained based on the «quasi-conformal similarity» condition of elementary rectangles [6] of two domains:

$$
\gamma=\frac{1}{(m+1)(n+1)} \sum_{i, j=0}^{m, n} \frac{\alpha_{i, j}+\alpha_{i, j+1}}{a_{i, j}+a_{i+1, j}}
$$

where

$$
\begin{gathered}
\alpha_{i, j}=\sqrt{\left(x_{i+1, j}-x_{i, j}\right)^{2}+\left(y_{i+1, j}-y_{i, j}\right)^{2}} \\
a_{i, j}=\left(\left(\kappa_{11}\left(y_{i, j+1}-y_{i, j}\right)-\kappa_{12}\left(x_{i, j+1}-x_{i, j}\right)\right)^{2}+\right. \\
\left.+\left(\kappa_{21}\left(y_{i, j+1}-y_{i, j}\right)-\kappa_{22}\left(x_{i, j+1}-x_{i, j}\right)\right)^{2}\right)^{\frac{1}{2}} .
\end{gathered}
$$

The numerical implementation of the algorithm is carried out as follows. Firstly, we set the domain $G_{\omega}$ partition parameters: $n$ and $m$, critical potential values $I^{*}, I^{0}$, parameters $\varepsilon_{1}, \varepsilon_{2}, \varepsilon_{3}$, which characterize the accuracy of the difference problem solution, parameter $\varepsilon_{4}$, which characterizes the accuracy of the investigated domain boundary identification. We set the outer contour $L_{1}^{*}=\left\{z: f^{*}(x, y)=0\right\}=\left\{x+i y: x=x_{1}^{*}(t)\right.$, $\left.y=y_{1}^{*}(t), \quad \alpha^{*}<t<\beta^{*}\right\}$ so that it is at a short distance from the inner one for the first problem. We set the initial approximation of the boundary nodes coordinates $\left(x_{0, j}^{(0)}, y_{0, j}^{(0)}\right),\left(x_{n, j}^{(0)}, y_{n, j}^{(0)}\right)$ (with monitoring the fulfillment of conditions (4)) and inner nodes $\left(x_{i, j}^{(0)}, y_{i, j}^{(0)}\right)$ (for example, evenly dividing the segments with the ends at the points $\left(x_{0, j}^{(0)}, y_{0, j}^{(0)}\right)$, $\left.\left(x_{n, j}^{(0)}, y_{n, j}^{(0)}\right)\right)$. Then we find the initial approximation $\gamma^{(0)}=\gamma\left(x_{i, j}^{(0)}, y_{i, j}^{(0)}\right)$ of the quasiconformal invariant $\gamma$ by formula (9). Next, we perform the 
refinement of the internal nodes coordinates $\left(x_{i, j}^{(\alpha)}, y_{i, j}^{(\alpha)}\right)$ with the given accuracy $\varepsilon_{1}$ ( $\alpha$ - the total iteration number) using iterative circuits such as the «cross» obtained by solving (7) with respect to $x_{i, j}$ and $y_{i, j}$. In this case, the necessary values of the pressure gradient and the permeability tensor $k$ in the grid nodes $G_{\omega}^{\gamma}$ are calculated from the values $x_{i, j}, y_{i, j}$ from the previous iteration step. We correct the boundary nodes, solving approximately the system of equations (8), for example, by Newton's method. If the value of the nodes displacement on the boundary for the performed $\alpha$-th total iteration

$$
S=\max _{i, j} \sqrt{\left(x_{i, j}^{(\alpha)}-x_{i, j}^{(\alpha-1)}\right)^{2}+\left(y_{i, j}^{(\alpha)}-y_{i, j}^{(\alpha-1)}\right)^{2}}
$$

$\left((i, j)\right.$ are indexes of the boundary nodes coordinates) is greater than $\varepsilon_{2}$, then we return to refine the internal nodes. Otherwise, we find new approximations $Q^{(L)}$ and $\gamma^{(L)}$ quantities $Q$ and $\gamma$ y the formula (9) and the condition for the connection between them: $Q=m \Delta \varphi \cdot \gamma$. If $\left|Q^{(L)}-Q^{(L-1)}\right|>\varepsilon_{3}$, then we return to the refinement of the internal nodes, otherwise we calculate the resulting grid «quasi-conformality» nonconnection $\delta=\sqrt{\delta_{1}^{2}+\delta_{2}^{2}}$, where $\delta_{1}, \delta_{2}$ are the equations approximations incompatibilities (3):

$$
\left\{\begin{array}{l}
\delta_{1}=\max _{i, j=1}^{n-1, m-1}\left|\gamma\left(x_{i+1, j}-x_{i-1, j}\right)-k_{i, j} \cdot\left(y_{i, j+1}-y_{i, j-1}\right)\right|, \\
\delta_{2}=\max _{i, j=1}^{n-1, m-1}\left|\gamma\left(y_{i+1, j}-y_{i-1, j}\right)+k_{i, j} \cdot\left(x_{i, j+1}-x_{i, j-1}\right)\right| .
\end{array}\right.
$$

Then we determine the position of the section lines of the hole, pressed and undamaged sections of the soil and set the outer contour $L_{2}^{*}=\left\{z: f^{*}(x, y)=0\right\}=\left\{x+i y: x=x_{2}^{*}(t), \quad y=y_{2}^{*}(t), \quad \alpha^{*}<t<\beta^{*}\right\} \quad$ so that it is somewhat «bigger» from the previous, and solve the problem for this contour. We compare the position of the section lines of the pressed and undisturbed soil plots for the first and second tasks. If the difference between them does not exceed $\varepsilon_{4}$, then the contour $L_{1}^{*}$ is sought, otherwise we go to the next task with the contour $L_{3}^{*}$, the results of which are compared with the results of the second one. 


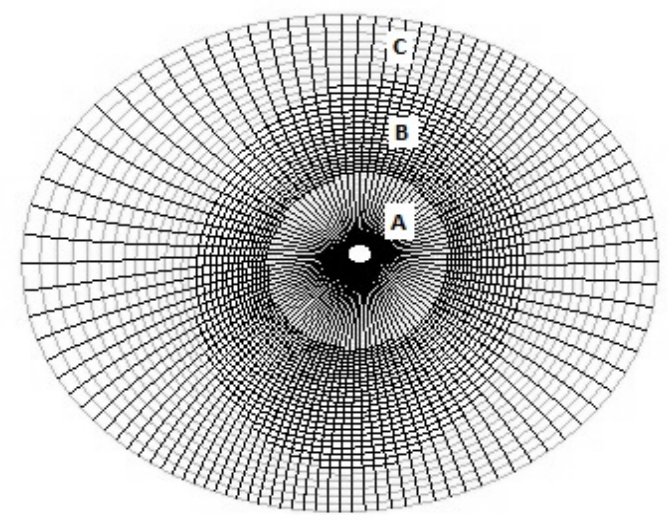

a)

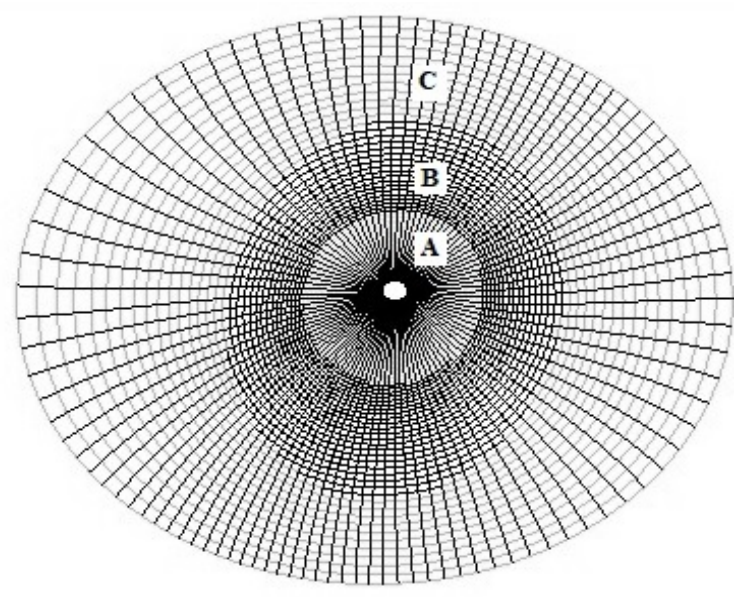

b)

Fig. 2. Distribution of zones formed by explosion

The process should be repeated until the difference between the section lines of the crater, the pressed and undisturbed zones for some $s$ and $s+1$ tasks will not satisfy the given accuracy. The contour $L_{s}^{*}$ is considered to be sought.

A computer program was developed and numerical calculations were performed based on the algorithm. For input data $n \times m=70 \times 100$, $I^{*}=0.008, I^{0}=0.004 . L_{*}=\left\{z: f_{*}(x, y)=0\right\}=\{x+i y: x=10+6 \cos (t)$, $y=5+5 \sin (t), \quad 0 \leq t<2 \pi\} \quad$ is charge contour, $\varphi_{*}=0, \quad \varphi^{*}=1$, 
$\beta=\left(\begin{array}{cc}0.1 & 0.15 \\ 0.05 & 0.06\end{array}\right)$, the original outer contour $L_{0}^{*}=\left\{z: f^{*}(x, y)=0\right\}=$ $=\{x+i y: x=48 \cos (t), y=39 \sin (t), 0 \leq t<2 \pi\}, k_{0}=\left(\begin{array}{ll}3 & 4 \\ 1 & 4\end{array}\right)$. The corresponding situational condition (in particular, the hydrodynamic field grid) resulting from the explosion in such medium is depicted in Fig. 2 a).

We see that 3 depreciated zones were created: A is a crater, B is a pressed zone, $\mathrm{C}$ is an undisturbed zone. The outer contour of the studied area is also identified: $L_{s}^{*}=\left\{z: f^{*}(x, y)=0\right\}=\{x+i y: x=160 \cos (t)$, $y=130 \sin (t), 0 \leq t<2 \pi\}$. For comparison Fig. 2b) shows the result of calculations for a predetermined external contour $L^{*}=\left\{z: f^{*}(x, y)=0\right\}=$ $=\{x+i y: x=176 \cos (t), \quad y=143 \sin (t), \quad 0 \leq t<2 \pi\}$. We see that the boundaries of the crater, pressed and undisturbed domains of the soil coincide.

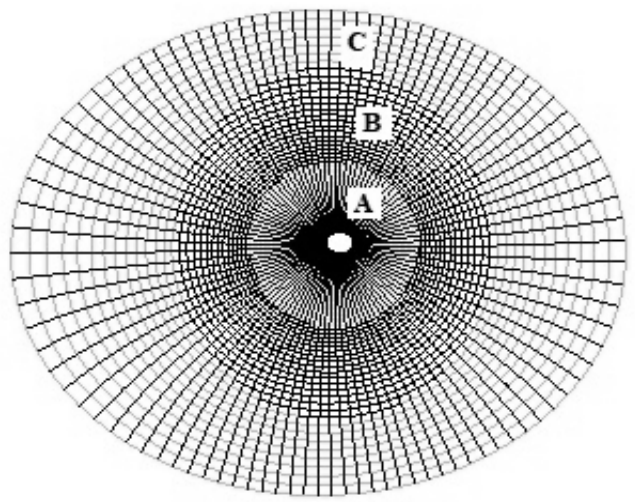

Fig. 3. Distribution of zones for an isotropic medium

Note that the algorithm works for an isotropic medium. Fig. 3 shows the results for anisotropy.

The input data is the same as for Fig. 2 only $k_{0}=\left(\begin{array}{ll}3 & 0 \\ 0 & 3\end{array}\right)$ (since the medium is isotropic). The outer contour is identified $L^{*}=$ $=\left\{z: f^{*}(x, y)=0\right\}=\{x+i y: x=144 \cos (t), \quad y=117 \sin (t), \quad 0 \leq t<2 \pi\}$.

We see that the anisotropy of the medium significantly influences the formation of a crater, the pressed and undisturbd domains of the soil, but the developed algorithm works for both the case of isotropy and for anisotropy. 
Conclusions. The mathematical model of the explosion process that takes into account the interaction of the process characteristics (quasipotential) and a deformable porous anisotropic medium based on the use of the numerical method of quasi-conformal mappings (as well as the algorithm for solving the corresponding nonlinear boundary-value problems) and aims to determine the position of the boundaries of the extruded, and unpolluted soil zones, is generally summarized in the case of identification and the boundary of the zone of influence of the explosion process on the medium. The solution of the corresponding boundary value problem occurs using the special procedure of inverse mapping and the stepwise parametrization of the medium characteristics and process, as well as the ideas of the block iteration method. This allows to automatically build a hydrodynamic grid and a speed field.

The results of the numerical experiments developed on the basis of the algorithm developed showed the feasibility of using it for modelling of explosive processes in anisotropic deformable porous medium in order to determine the position of the section lines of the crater, the pressed and undisturbed zones of the soil with the simultaneous identification of the boundary of the explosion impact zone. It is shown that the developed algorithm works for both anisotropic medium and for isotropic.

In the perspective is identification of the explosion process parameters, in particular, finding the location and the shape of the charge, as well as solving the corresponding spatial problems.

\section{References:}

1. Kravets V. G. Physical processes of applied geodynamics of an explosion: monograph / V. G. Kravets, V. V. Korobyichuk, V. V. Boiko. - Zhytomyr : ZSTU, 2015. - $408 \mathrm{p}$.

2. Bulavatskii V. M.. Some inverse problems of the pulsed-hydrodynamic theory of explosion on the discharge / V. M. Bulavatskii, I. A. Luchko // Investigations on boundary value problems of hydrodynamics and thermophysics. Kiev, 1979. - P. 53-64.

3. Bomba A. Ya. Nonlinear mathematical models of geohydrodynamics processes / A. Ya. Bomba, V. M. Bulavatskii, V. V. Skopetskii. — Kiiv : Naukova dumka, 2007. $-308 \mathrm{p}$.

4. Bomba A. Ya. Using quasi-conformal mappings to mathematical modeling of explosion processes / A. Ya. Bomba, A. M. Sinchuk // Volynskii matematychnii visnyk. Serie «Applied mathematics». - Ed. 8. - P. 32-41.

5. Bomba A. Ya. Modeling of the explosion process in an anisotropic medium with quasiconformal mapping methods/ A. Ya. Bomba, K. M. Malash // Transactions of Kremenchuk Mykhailo Ostrohradskyi National University. - Kremenchuk. - 2017. Ed. 4 (105). - P. 28-33.

6. Bomba A. Ya. Methods of complex analysis: monograph / A. Ya. Bomba, S. S. Kashtan, D. O. Prigornytskii, S. V. Yaroshchack. — Rivne : NUWM, 2013. - 415 p.

7. Blair David E. Inversion theory and conformal mapping / David E. Blair. American Mathematical Sciety, 2000. - 152 p. 
8. Nearling James. Mathematical tools for physics / James Nearling. - Miami, 2008. - $594 \mathrm{p}$.

9. Prigornitskii D. O. Modification of the algorithm for numerical solving a class of nonlinear modeling boundary value problems on quasi-conformal mappings in twocoupling deformable media / D. O. Prigornitskii // Volynskii matematychnii visnyk - Serie «Applied mathematics ». — Ed. 9. - 2002. — P. 60-66.

10. Bomba A. Ya. Numerical solution of nonlinear modeling boundary value problems on quasi-conformal mapping under conditions of interaction of gradients of potential and environmental characteristics / A. Ya. Bomba, V. V. Skopetskii, D. O. Prigornitskii // Visnyk Kiivskoho Universitetu. Serie: «Physics and mathematics». - 2003. - Ed. 1. - P. 126-135.

\section{МОДЕЛЮВАННЯ ВИБУХОВИХ ПРОЦЕСІВ В АНІЗОТРОПНОМУ СЕРЕДОВИЩІ 3 ІДЕНТИФІКАЦІЄЮ МЕЖІ ЗОНИ ВПЛИВУ}

У наші дні для оптимізації процесів видобування корисних копалин, у будівництві та промисловості досить поширеною є практика застосування вибухових процесів. Вона дозволяє значно підвищити швидкість виконання робіт i, водночас, знизити їх вартість. Проте, побічні дії застосування вибухівки можуть бути катастрофічними, оскільки ії руйнівна сила здатна повністю зносити навіть досить стійкі споруди та завдавати непоправної шкоди навколишньому середовищу, тому $є$ необхідність попереднього точного математичного моделювання вибухового процесу з детальним прорахуванням усіх його наслідків.

Однією з моделей, котрі застосовуються для дослідження вибухового процесу, є рідинна, яка базується на моделюванні середовища, у якому відбувається вибух, як нестискуваної фільтраційної рідини. При цьому поле швидкостей, породжене вибухом, як правило, вважається потенціальним.

У статті сформовано математичну модель процесу вибуху, яка базується на рідинній. Вона враховує взаємовплив параметрів деформівного анізотропного пористого середовища та характеристик вибухового процесу. Відповідна крайова задача розв'язується з використанням числового методу квазіконформних відображень, що забезпечує можливість іiі розв'язання з врахуванням наявності зворотного впливу, існування якого суттєво ускладнює процес розв'язування задачі іншими, менш «динамічними», методами. Адаптовано алгоритм розв'язування крайових задач, що використовуються при моделюванні аналогічних процесів у гідродинаміці та електродинаміці, зокрема, для дослідження фільтраційних процесів та електротомографії. Розроблено методику ідентифікації зовнішньої межі області впливу вибухового процесу шляхом внесення певних змін до «класичного» алгоритму для розв'язування такого типу крайових задач для двозв'язної області, оскільки останній вимагає апріорного задання внутрішнього та зовнішнього контурів області.

Ключові слова: анізотропне середовище, вибухові прочеси, гідродинамічна сітка, ідентифікація, квазіконформне відображення, комплексний аналіз, математичне моделювання, числові методи.

Отримано: 20.11.2018 